\title{
Childhood Neuroblastoma
}

National Cancer Institute

\section{Source}

National Cancer Institute. Childhood Neuroblastoma. NCI Thesaurus. Code C124270.

A neuroblastoma that occurs during childhood. 